\title{
Proportion of Japanese outpatients filling prescriptions for long-term medication regimens
}

This article was published in the following Dove Press journal:

Patient Preference and Adherence

\author{
Kaori Kurata' \\ Michi Onuki ${ }^{2}$ \\ Kazuki Yoshizumi ${ }^{3}$ \\ Eitaro Taniai ${ }^{3}$ \\ Akira Dobashi \\ 'Education and Research Institute of \\ Information Science, Tokyo University of \\ Pharmacy and Life Sciences, Hachioji, \\ Tokyo, Japan; ${ }^{2}$ Insurance Pharmacy \\ Division, Yakuju Co. Ltd, Minato- \\ ku, Tokyo, Japan; ${ }^{3}$ Information \\ Headquarters, Yakuju Co. Ltd., Yamato- \\ shi, Kanagawa, Japan
}

\begin{abstract}
Aim: Our study aimed to clarify how long outpatients with chronic diseases such as hypertension continuously fill prescriptions for the same medications as those prescribed initially and how many medications they take over the long term.

Methods: Medication records from April 1, 2016 to March 31, 2017 with total days between initial and final dispensation date $\geq 330$ days and total days of medication supplies $\geq 180$ days were extracted from an electronic database in a Japanese community pharmacy chain. The continuity of refilling medications over 1 year (ie, medication fill adherence) was measured using the medication possession ratio (MPR).

Results: A total of 34,549 outpatients received long-term medications under the above conditions (4.4\% of all patients in the database). Mean age was $66.0 \pm 17.4$ years; $63.1 \%$ were $\geq 65$ years. The mean number of medications prescribed per patient was $3.2 \pm 2.3$. More than one-fifth of patients $(22.6 \%)$ were taking $\geq 5$ medications. The mean MPR for patients overall was $93.6 \pm 11.2 \%$; $87.2 \%$ of patients had an MPR $\geq 80 \%$ but $<110 \%$. Amlodipine besylate, an antihypertensive, was the most commonly prescribed drug ( $\mathrm{n}=5,537$ patients).

Conclusion: Outpatients that received long-term medications with no change in prescription had an MPR $>90 \%$ for around 3 medications. It can be reasonably assumed that these patients could receive a longer-term medication supply with the partial fills based on a physician's instruction ("Bunkatu Chozai" in Japanese). This longer-term supply would be similar to a basic prescription refill, but would require a physician's signature allowing for partial refills rather than a new prescription for each refill.
\end{abstract}

Keywords: outpatient, partial fill, long-term medication, medication possession ratio, chronic disease, refill prescription

\section{Introduction}

Outpatients with chronic diseases such as hypertension, diabetes mellitus, dyslipidemia, and hyperuricemia usually take medications over long periods. Prescriptions for these medications generally do not change as long as the patient's condition is stable and/or adverse events do not occur.

In Japan, almost all outpatients receive their medications on the day they are prescribed because, under the national health insurance program, prescriptions expire in 4 days. Furthermore, the Japanese national health system has not adopted a refill (or a repeat) prescription program, and the number of total days of medication supplies per single prescription is lower than that in other countries. For example, according to a Survey of Medical Care Activities in Public Health Insurance, ${ }^{1}$ distribution of the number of prescription days for all medications prescribed in 2016 was as follows: $\leq 14$ days, $87.6 \%$; $\geq 15$ days to $\leq 30$ days,
Correspondence: Akira Dobashi Education and Research Institute of Information Science, Tokyo University of Pharmacy and Life Sciences, I432-I Horinouchi, Hachioji, Tokyo 192-0392, Japan

Tel +8I 426763082

Fax +81 426707067

Email dobashi@toyaku.ac.jp 
$8.7 \%$, and $\geq 31$ days, $3.7 \%$. Prescription days per one single prescription are generally unlimited to the range that a physician in Japan foresees current medical condition lasting, and the proportion of prescriptions written for $\geq 31$ days was very small.

However, outpatients with chronic diseases often take the same medications as those prescribed initially over the long term, so that actual number of days of medication supplies are longer than the prescription days reported in the survey above. Our study aimed to clarify how long they fill prescriptions for the same medications and how many medications they continuously take over 1 year. Based on our findings, we will discuss the possibility that these patients should receive a longer-term medication supply with partial fills by physician's instructions ("Bunkatu Chozai" in Japanese), similar to a basic prescription refill.

\section{Methods}

Medication records, including medicines prescribed repeatedly over 1 year, were extracted from an electronic database in a community pharmacy chain (Yakuju Co. Ltd.), consisting of 155 stores in the Japanese Kanto region (eastern half of Japan, including Tokyo). Medication records were collected from April 1, 2016, to March 31, 2017, and were anonymized to protect personal information. Outpatient records that showed total days between initial and final dispensation date $\geq 330$ days and total days of medication $\geq 180$ days for individual medications were included in this analysis. In addition, sex, age, and the date that medications prescribed for patients were filled in community pharmacies (ie, the dispensation date) were collected. The medicines were identified by individual medicine codes of Japan (referred to as YJ codes), brand names, and generic names.

The medication possession ratio (MPR) was used to assess medication fill adherence. ${ }^{2-8}$ The MPR was defined as the total days of medication supplies by prescription divided by the observation period that starts at the first dispensation date and ends at the last dispensation date for individual medications, and expressed as a percentage. ${ }^{4}$ Days' supply beyond the end of the observation period was excluded. When MPR is $>100 \%$, it indicates that there may be overlaps in days between taking medications; this may leave medicines not taken regularly. When MPR is $<100 \%$, it indicates that there may be gaps in the days between taking medications. As has been reported extensively in the literature describing adherence rates for refilled prescriptions, medication refill adherence is considered satisfactory if MPR is $\geq 80 \%{ }^{5,6}$ Although MPR cannot ensure that patients are taking their medications, it provides an estimate of the highest possible level of medication consumption over a particular time frame.

Medication records of patients with the same prescription $\geq 2$ times, each for $\geq 14$ days, were collected by individual medications. Among these records, those having an observation period $\geq 330$ days and total days of medication supplies $\geq 180$ days were considered to be taking long-term medications. These records were extracted from the collected record and summed for each patient. Both mean MPR and the proportion of patients taking medications with an MPR $\geq 80 \%$ but $<110 \%$ were calculated; these values were compared between males and females, patients $\geq 65$ years and $<65$ years, and between those taking $\geq 5$ medications and $<5$ medications.

The ethics committee of the Social University (the General Incorporated Association, 8-5-26 Akasaka, Minatoku, Tokyo, Japan) approved this study (approval day: March 16, 2017; approval number: SU-0005). Informed consent for each outpatient corresponding to the medication record stored in the database was not needed because the medication records analyzed in our study were anonymized in a linkable fashion according to the requirement for protection of personal information.

\section{Statistical analysis}

Statistical tests were performed using JMP Pro 14 (SAS, 6-10-1 Roppongi, Minato-ku, Tokyo, Japan). Chi-square test $(P, 0.001)$ was used to determine differences in the proportion of patients with an MPR $\geq 80 \%$ but $<110 \%$ between males and females, between the two age groups ( $\geq 65$ years and $<65$ years), and between two medication groups ( $\geq 5$ medications and $<5$ medications).

\section{Results}

Medication records for the 1-year survey included 787,451 outpatients. Among these patients, 158,938 (20.2\%) had medications prescribed more than twice and with each medication prescribed for $\geq 14$ days. Of these patients, 34,549 ( $4.4 \%$ of all patients in the database) received medications for $\geq 330$ total days between initial and final dispensation date and $\geq 180$ total days of medication supplies. Records for these patients were included in this analysis.

The mean age of patients was $66.0 \pm 17.4$ years, $49.2 \%$ of male, and 21,789 (63.1\%) were $\geq 65$ years (Table 1 ). 
Table I Characteristics of patients receiving long-term and repeat medications and those taking $\geq 5$ medicines versus $<5$ medicines

\begin{tabular}{|c|c|c|c|}
\hline & $\begin{array}{l}\text { Total } \\
34,549 \\
(100 \%)\end{array}$ & $\begin{array}{l}<5 \text { medica- } \\
\text { tions } \\
26,720 \\
(77.3 \%)\end{array}$ & $\begin{array}{l}\geq \mathbf{5} \text { medica- } \\
\text { tions } \\
7,829 \\
(22.7 \%)\end{array}$ \\
\hline Age (SD), years & $\begin{array}{l}66.0 \\
(17.4)\end{array}$ & $64.6(17.8)$ & $71.0(15.0)$ \\
\hline$<65$ years & $\begin{array}{l}12,760 \\
(36.9 \%)\end{array}$ & $10,638(39.8 \%)$ & $2,122(27.1 \%)$ \\
\hline$\geq 65$ years & $\begin{array}{l}21,789 \\
(63.1 \%)\end{array}$ & $16,082(60.2 \%)$ & 5,707 (72.9\%) \\
\hline Male & $\begin{array}{l}16,980 \\
(49.2 \%)\end{array}$ & $12,973(48.6 \%)$ & 4,007 (5।.2\%) \\
\hline $\begin{array}{l}\text { Prescription days } \\
\text { (SD) }\end{array}$ & $\begin{array}{l}33.2 \\
(15.6)\end{array}$ & $33.8(15.9)$ & $31.1(14.4)$ \\
\hline$<10$ days & $\begin{array}{l}307 \\
(0.9 \%)\end{array}$ & 238 (0.9\%) & 69 (0.9\%) \\
\hline $10-40$ days & $\begin{array}{l}27,279 \\
(79.0 \%)\end{array}$ & $17,816(66.7 \%)$ & $6,460(82.5 \%)$ \\
\hline$\geq 40$ days & $\begin{array}{l}6,963 \\
(20.2 \%)\end{array}$ & 8,666 (32.4\%) & $1,300(16.6 \%)$ \\
\hline Medications (SD) & $3.2(2.3)$ & $2.2(\mathrm{I} . \mathrm{I})$ & 6.7 (1.9) \\
\hline $\begin{array}{l}\text { Total days of med- } \\
\text { ication supplies } \\
\text { (SD) }\end{array}$ & $\begin{array}{l}320.5 \\
(39.1)\end{array}$ & $317.2(40.9)$ & $332.0(29.1)$ \\
\hline $\begin{array}{l}\text { Medication pos- } \\
\text { session ratio } \\
\text { (MPR) (SD), \% }\end{array}$ & $\begin{array}{l}93.6 \\
(11.2)\end{array}$ & $92.6(11.8)$ & $96.8(8.2)$ \\
\hline$<80 \%$ & $\begin{array}{l}3,936 \\
(11.4 \%)\end{array}$ & 3,633 (13.6\%) & 303 (3.9\%) \\
\hline $80-110 \%$ & $\begin{array}{l}30,142 \\
(87.2 \%)\end{array}$ & 22,745 (85.1\%) & 7,397 (94.5\%) \\
\hline$\geq 110 \%$ & $\begin{array}{l}471 \\
(1.4 \%)\end{array}$ & 342 (I.3\%) & $129(1.6 \%)$ \\
\hline
\end{tabular}

\section{Prescription days and total days of medication supplies}

The mean prescription days per single patient was 33.2 \pm 15.6 days (Table 1 ). The mean total days of medication supplies was $320.5 \pm 39.1$ days within a mean observation period of $342.6 \pm 8.1$ days. A total of $80.5 \%$ received medications for $\geq 300$ days. Thus, outpatients generally received, on average, medications around 10 times with a 33-day supply of the prescription from a community pharmacy per year.

A total of $79.0 \%$ of patients had a mean number of prescription days $\geq 10$ days but $<40$ days. A total of $20.2 \%$

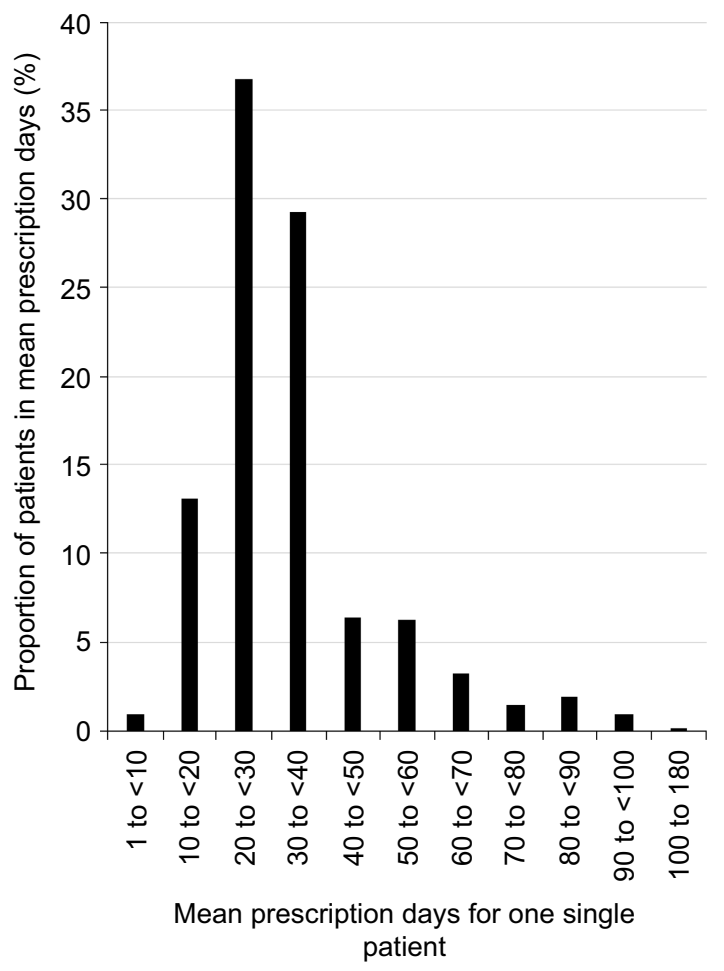

Figure I Frequency distribution of mean prescription days per one single patient for long-term medications. Minimum value of mean prescription days was 4.5 -day $(n=1)$ and maximum value 180 -day $(n=2)$.

had the prescription days $\geq 40$ days, and only $0.9 \%$ had the prescription days $<10$ days. The frequency distribution of the mean prescription days ranged from 4.5 to 180 days (Figure 1).

As can be seen in Figure 1, the proportion of the prescription days $\geq 30$ days was considerably higher than that reported by a Survey of Medical Care Activities in Public Health Insurance (3.73\% for $\geq 31$ days,). ${ }^{1}$ Around one-half $(49.4 \%)$ of patients in this study received longterm and repeat medications with the prescription days $\geq 30$ days.

\section{Number of medications}

The number of medications prescribed per patient ranged from 1 to 22 for long-term and repeat medications (Figure 2). The mean number of medications prescribed was $3.2 \pm 2.3$ (Table 1). More than one-fifth of patients $(22.7 \%)$ were taking $\geq 5$ medications. There was a significant difference between males and females in those taking $\geq 5$ medications (male, $51.2 \%$; female, $48.8 \% ; p<0.0001)$.

Among all patients, 7,829 (51.2\% male) were taking $\geq 5$ medications and 26,720 patients were taking $<5$ medications $(48.6 \%$ male). In addition, patients taking $\geq 5$ 


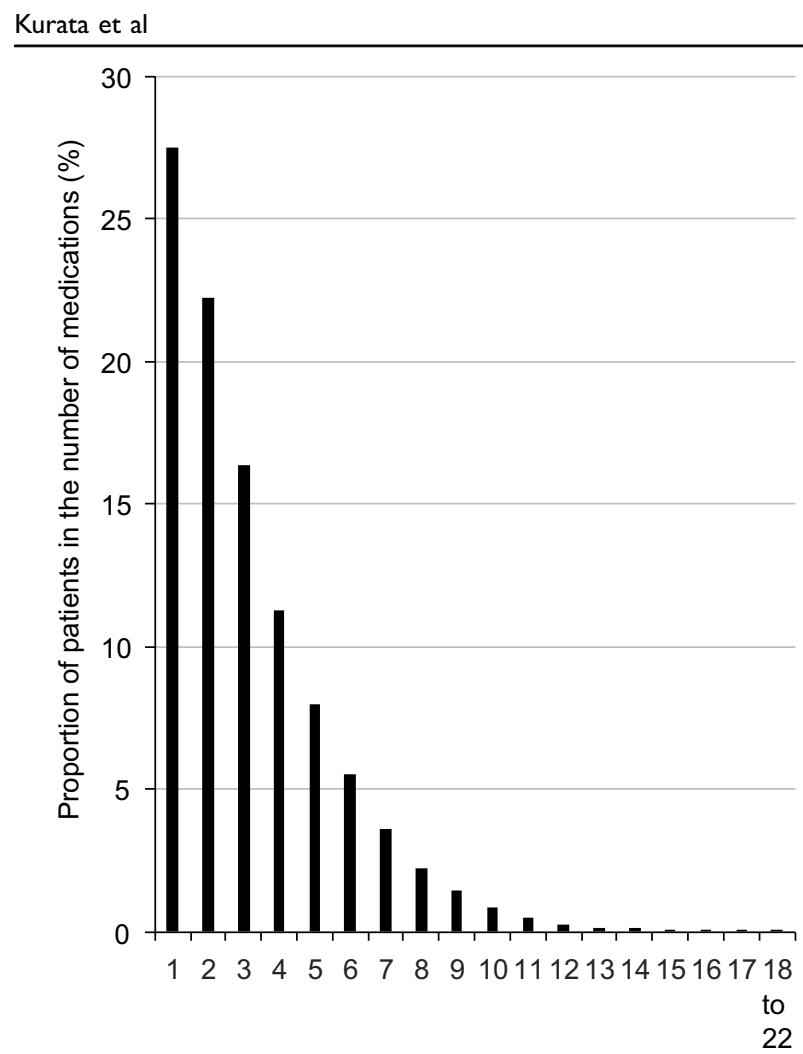

Number of medications

Figure 2 Number of long-term medications prescribed per patient.

medications were significantly more likely to be elderly ( $\geq 65$ years vs $<65$ years, $72.9 \%$ vs $60.2 \%$, respectively; $P<0.0001$ ).

\section{Medication possession ratio (MPR)}

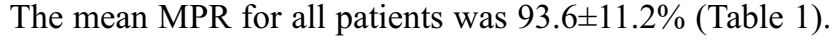
A total of $87.2 \%$ of patients had an MPR $\geq 80 \%$ but $<110 \%$. A total of $11.4 \%$ had an MPR $<80 \%$, and only $1.4 \%$ had an MPR $\geq 110 \%$. The frequency distribution of MPR ranged from $49.5 \%$ to $302.7 \%$ (Figure 3).

Patients taking $\geq 5$ medications were significantly more likely to have an MPR $\geq 80 \%$ but $<110 \%$ compared with those taking $<5$ medications ( $94.5 \%$ vs $85.1 \%$, respectively; $P<0.0001$ ) (Table 1).

\section{Representative medications prescribed for the long term}

A total of 881 medications were prescribed repeatedly over 1 year. Table 2 shows the top 20 medications along with their anatomical therapeutic chemical (ATC) classification. These 20 medications had a mean MPR ranging from $92.7 \%$ to $96.4 \%$, a mean of prescription days per patient ranging from 25.2 to 38.1, and a total days' supply (accumulated from all values except the last prescription day) ranging from 317.4 to 331.3 .

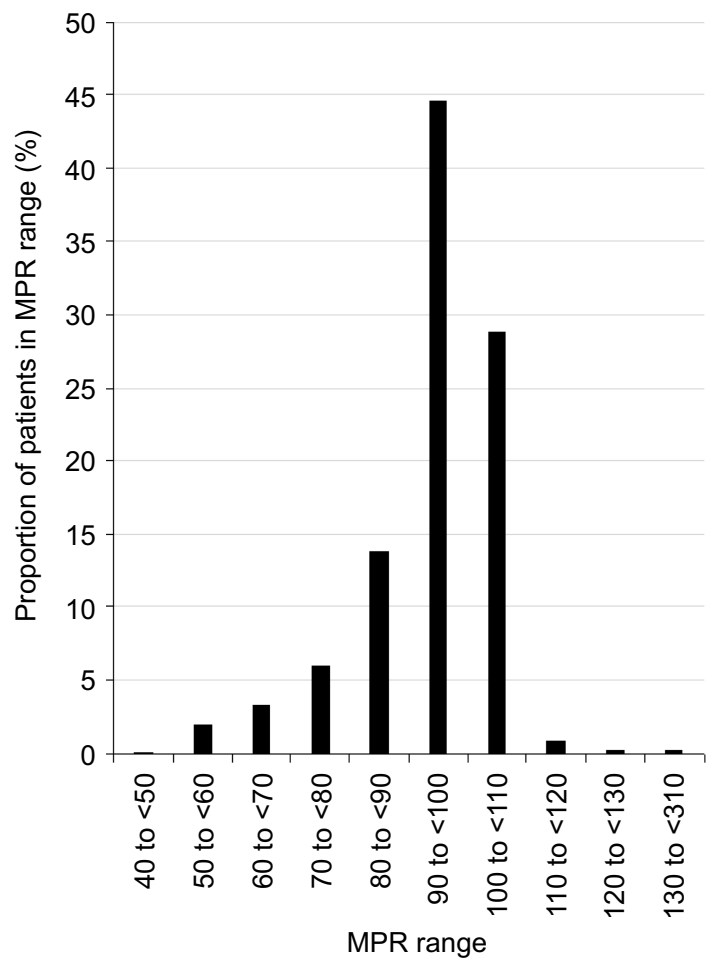

Figure 3 Frequency distribution of medication possession ratio (MPR) for long-term medications. Minimum value of MPR was $49.5 \%(n=1)$ and maximum value $302.7 \%$ $(n=1)$.

Amlodipine besylate, an antihypertensive, was prescribed for the highest number of patients. This drug showed a mean MPR of $95.5 \% \pm 9.2 \%$, a mean of 33.8 \pm 14.6 prescription days per patient, and a mean of 326.9 \pm 32.4 total medication days.

Among the 20 medications, eleven medications were included in four therapeutic categories related to chronic diseases shown in Table 3.

\section{MPR of medications based on therapeutic category}

Hypertensive agents were the most commonly prescribed drugs, followed by dyslipidemic agents, antidiabetic agents (limited to oral and non-insulin agents), and hyperuricemia agents (Table 3). The mean MPR for all four agents was $\geq 90 \%$ and the proportion of patients with an MPR range of $80-110 \%$ was also $\geq 90 \%$.

\section{Discussion}

Our study found that around 4\% of Japanese outpatients generally received 3 medications with a 33-day filling period over 10 pharmacy visits during 1-year survey. The medication fill adherence was, on average, estimated at over $90 \%$. Of these patients, those taking $\geq 5$ medications 
Table 2 Number of days and medication possession ratio (MPR) for top 20 medicines prescribed overall

\begin{tabular}{|c|c|c|c|c|c|}
\hline Generic drug name & $\begin{array}{l}\text { ATC } \\
\text { classification }^{\mathbf{a}}\end{array}$ & $\mathbf{n}$ & $\begin{array}{l}\text { Average prescription } \\
\text { days per patient (SD) }\end{array}$ & $\begin{array}{l}\text { Total days with } \\
\text { prescription supplies } \\
\text { (SD) }\end{array}$ & $\begin{array}{l}\text { MPR (SD), } \\
\%\end{array}$ \\
\hline Amlodipine besylate & $\mathrm{CO8}$ & 5,537 & $33.8(14.6)$ & $326.9(32.4)$ & $95.5(9.2)$ \\
\hline Rosuvastatin calcium & CIO & 2,436 & $34.5(14.5)$ & $322.335 .0)$ & $94.2(10.0)$ \\
\hline Aspirin & $\mathrm{BOI}$ & 2,258 & $34.9(16.9)$ & $329.4(29.7)$ & $96.1(8.4)$ \\
\hline Magnesium oxide & $\mathrm{A} 02, \mathrm{~A} 06, \mathrm{~A} 12$ & 2,172 & $30.3(15.8)$ & $325.1(42.2)$ & $94.6(12.0)$ \\
\hline Atorvastatin calcium hydrate & CIO & 2,044 & $34.3(14.8)$ & $325.9(31.9)$ & $95.2(9.1)$ \\
\hline Lansoprazole & $\mathrm{A} 02$ & 1,852 & $33.2(15.2)$ & $328.8(32.0)$ & $96.0(9.0)$ \\
\hline Etizolam & N05 & I,784 & $27.0(8.9)$ & $331.3(60.7)$ & $96.4(17.3)$ \\
\hline Nifedipine & $\mathrm{Co8}$ & 1,657 & $33.9(14.9)$ & $328.6(32.2)$ & $96.0(9.2)$ \\
\hline Pitavastatin calcium hydrate & CIO & $\mathrm{I}, 586$ & $34.4(14.1)$ & $326.3(31.0)$ & $95.3(8.9)$ \\
\hline Candesartan cilexetil & $\mathrm{CO9}$ & $\mathrm{I}, 464$ & $35.0(15.5)$ & $327.0(31.5)$ & $95.5(9.0)$ \\
\hline Telmisartan & $\mathrm{CO9}$ & 1,442 & $34.4(14)$ & $329.4(29.2)$ & $96.2(8.2)$ \\
\hline Brotizolam & N05 & 1,345 & $25.2(6.0)$ & $324.0(52.7)$ & $94.5(15.1)$ \\
\hline Allopurinol & M04 & 1,327 & $34.7(16.0)$ & $324.4(33.6)$ & $94.8(9.6)$ \\
\hline Zolpidem tartrate & N05 & 1,305 & $25.6(5.7)$ & $317.4(52.0)$ & $92.6(14.9)$ \\
\hline Febuxostat & M04 & 1,259 & $34.8(15.2)$ & $324.4(33.6)$ & $94.8(9.5)$ \\
\hline $\begin{array}{l}\text { Esomeprazole magnesium } \\
\text { hydrate }\end{array}$ & $\mathrm{A} 02$ & 1,230 & $34.3(15.5)$ & $324.6(38.5)$ & $94.8($ (II.I) \\
\hline Sitagliptin phosphate hydrate & Alo & 1,205 & $36.7(15.5)$ & $328.9(27.3)$ & $96.2(7.7)$ \\
\hline Rebamipide & $\mathrm{A} 02$ & 1,195 & $30.4(14.3)$ & $318.0(46.0)$ & $92.7(13.3)$ \\
\hline Famotidine & $\mathrm{A} 02$ & 1,188 & $32.4(16.3)$ & 329.1 (31.4) & $95.9(8.9)$ \\
\hline Metformin hydrochloride & Alo & 1,101 & $38.1(15.0)$ & $323.7(33.4)$ & $94.7(9.7)$ \\
\hline
\end{tabular}

Note: ${ }^{\text {aACT }}$ classification of being bold indicates that these medications are included in four therapeutic categories related to chronic diseases shown in Table 3. Abbreviation: ATC, anatomical therapeutic chemical.

were significantly more likely to be $\geq 65$ years higher and in the proportion with an MPR $\geq 80 \%$ but $<110 \%$ than those taking $<5$ medications.

MPR estimates the proportion of times that medications are filled over a particular observation period and the highest possible level of medication consumption. ${ }^{2-4}$ Based on the MPR values in our study, patients received medications prescribed by their physicians regularly. These findings are particularly important for patients undergoing long-term medical treatment and indicate that patients are making regular physician visits, as medications are not automatically refilled in Japan.

In a medication refill adherence study using a pharmacy claims database among patients with chronic diseases in the United State, ${ }^{7}$ MPR $\geq 80 \%$ was detected for $72.3 \%$ of patients with hypertension and $65.4 \%$ with type 2 diabetes mellitus.

In our study, the MPR was $\geq 90 \%$ for the topmost frequently prescribed medications, which is higher than that shown in the previous study. An adherence study of patients with chronic diseases receiving Medicaid in the United States found a mean MPR for a 30-day refill of medications of $71 \%$ in patients with hypertension and $69 \%$ for patients with type 2 diabetes mellitus, and a mean MPR for a 90 -day refill of $83 \%$ and $80 \%$, respectively. ${ }^{8}$ The 33-day refill period in our study is similar to the 30-day period in the Medicaid study, although MPR findings were higher in our study.

The one way that prescriptions in Japan can be filled partially ("Bunkatu Chozai" in Japanese) is when it is difficult to preserve the medication for a long period; in these cases, medications are partially filled and the remaining portion is filled at a later time. Another way for partial filling of prescriptions is according to the physicians' indications, which is similar to refilling prescriptions based on a specified number of refills before a certain expiration date. Thus, patients can obtain more of the same medications from pharmacists without seeing the prescribers within a total of the prescription days and 4 days of the prescription expiration date. ${ }^{9}$ This novel prescription format introduced in 2018 allows physicians to prescribe a partial days' supply, and the number of partial fills of prescriptions in the remarks column of prescription sheets. 
Table 3 Mean medication possession ratio (MPR) for four therapeutic categories

\begin{tabular}{|c|c|c|c|c|c|c|c|}
\hline \multirow{3}{*}{$\begin{array}{l}\text { Therapeutic } \\
\text { classification }\end{array}$} & \multirow{3}{*}{$\begin{array}{l}\text { ATC } \\
\text { classification }\end{array}$} & \multicolumn{6}{|c|}{ Patients taking medications by therapeutic classification } \\
\hline & & \multirow[t]{2}{*}{$\mathbf{n}$} & \multirow{2}{*}{$\begin{array}{l}\text { Age (SD), } \\
\text { years }\end{array}$} & \multirow{2}{*}{$\begin{array}{l}\text { Male, } \\
\%\end{array}$} & \multirow{2}{*}{$\begin{array}{l}\text { MPR } \\
\text { (SD), \% }\end{array}$} & \multicolumn{2}{|l|}{$\mathbf{n}$} \\
\hline & & & & & & $\begin{array}{l}\text { MPR range of } \\
80-110 \%\end{array}$ & $\begin{array}{l}\text { MPR range of } \\
\geq 110 \%\end{array}$ \\
\hline Hypertension agents & $\mathrm{C} 02-\mathrm{C} 09$ & $14,824(42.9 \%)$ & $71.7(11.8)$ & 51.8 & $95.9(8.9)$ & $20,396(92.9 \%)$ & $200(0.9 \%)$ \\
\hline Dyslipidemia agents & $\mathrm{ClO}$ & $8,838(25.6 \%)$ & $70.2(11.4)$ & 45.2 & $95.1(9.3)$ & $8,507(91.9 \%)$ & $65(0.7 \%)$ \\
\hline Antidiabetic agents & A 10 & $4,252$ ( $12.3 \%)$ & $68.5(11.5)$ & 60.1 & $95.6(8.6)$ & 6,841 (92.9\%) & $53(0.8 \%)$ \\
\hline Hyperuricemia agents & M04 & $2,883(8.3 \%)$ & $67.8(13.4)$ & 85.1 & $94.5(9.8)$ & 2,744 (90.7\%) & $21 \quad(0.7 \%)$ \\
\hline
\end{tabular}

Abbreviation: ATC, anatomical therapeutic chemical.

The process for partial filling of a prescription in Japan differs substantially from that in the United States, where partial filling of a prescription is permitted when the pharmacist is unable to supply the prescribed amount or the prescriber requests less than the full quantity called for in a prescription.

Our study indicated that outpatients who repeatedly received the same medications as prescribed initially and who had a medication supply $\geq 180$ days during this 1-year survey showed high adherence to both visiting their physicians to obtain a prescription. It is reasonable to assume that outpatients should be able to receive a long-term supply of medication (eg, 90 days), with an order for partial filling on the part of the physician, and without the need for a new prescription for each refill.

When this partial filling of prescriptions is expanded and extended, community pharmacists should regularly consult with patients about taking their medications as prescribed, not only to help them understand the need to continue treatment, but also to enhance their medication adherence. These consultations may also help to reduce polypharmacy, which is common in people aged $\geq 65$ years. These elderly patients may have a greater risk for polypharmacy, that is, inappropriate use of multiple drugs, and should be considered in efforts to reduce unnecessary polypharmacy. ${ }^{10}$

\section{Limitations}

First, our study used MPR to estimate medication fill adherence. Although systematic reviews have shown that MPR is a reliable measure of adherence, ${ }^{2}$ our study cannot report actual adherence to taking medications. However, we can discuss continuity and regularity of Japanese outpatients in terms of behavior regarding receiving their medicines from a community pharmacy. Regular receipt of medications may mean that medications are being used. However, this could not be proven in our study.

Second, there are pharmacies within community pharmacy chains and individual pharmacies in Japan. Our study was based on medication records stored in a community pharmacy chain. This chain is controlled by a management headquarters, which may influence which medications are used. However, as medications are filled as prescribed by physicians in terms of both brand and generic medicines, the headquarters does not control the medication used except when a generic medicine is prescribed by the physician. Thus, all branches within Yakuju are similar to individual pharmacies, limiting the possibility for differences between these pharmacies.

\section{Conclusion}

Our study found that Japanese outpatients who repeatedly received the same medications as prescribed initially and who had a medication supply $\geq 180$ days over 1 year were around $4 \%$ of all and showed high medication fill adherence over $90 \%$. It is reasonably assumed that these patients could receive a longer-term medication supply with the novel partial fills based on a physician's instruction ("Bunkatu Chozai" in Japanese). This prescription format introduced in 2018 would be similar to a basic prescription refill and allows physicians to prescribe a partial days' supply, and the number of partial fills of prescriptions.

\section{Disclosure}

The authors report no conflicts of interest in this work. 


\section{References}

1. Survey of Medical Care Activities in Public Health Insurance 2016, Use of drugs, Table 6. [Publication day; July 25, 2017]. Available from: https://www.e-stat.go.jp/stat-search/files?page=1\&layout=data list \& touke $=00450048 \&$ tstat $=000001029602 \&$ cycle $=7 \&$ tclass $1=$ $000001103215 \&$ tclass $2=000001103256 \&$ tclass $3=000001103259 \& \mathrm{sec}$ ond $2=1$. Accessed July 27, 2018. Japanese.

2. Hess LM, Raebel MA, Conner DA, Malone DC. Measurement of adherence in pharmacy administrative databases: a proposal for standard definitions and preferred measures. Ann Pharmacother. 2006;40 (7-8):1280-1288. doi:10.1345/aph.1H018

3. Sattler EL, Lee JS, Perri M. 3rd, Medication (re)fill adherence measures derived from pharmacy claims data in older Americans: a review of the literature. Drugs Aging. 2013;30(6):383-399. doi:10.1007/ s40266-013-0074-z

4. Arnet I, Abraham I, Messerli M, Hersberger KE. A method for calculating adherence to polypharmacy from dispensing data records. Int J Clin Pharm. 2014;36:192-201. doi:10.1007/s11096-013-9891-8

5. Feehan M, Ranker L, Durante R, et al. Adherence to controller asthma medications: 6-month prevalence across a US community pharmacy chain. $J$ Clin Pharm Ther. 2015;40(5):590-593. doi: $10.1111 /$ jcpt. 12316
6. Feehan M, Munger MA, Cooper DK, et al. Adherence to glaucoma medications over 12 months in two US community pharmacy chains. $J$ Clin Med. 2016;5(9):79-86. doi:10.3390/ jem5090079

7. Briesacher BA, Andrade SE, Fouayzi H, Chan KA. Comparison of drug adherence rates among patients with seven different medical conditions. Pharmacotherapy. 2008;28(4):437-443. doi:10.1592/ phco.28.4.437

8. Taitel M, Fensterheim L, Kirkham H, Sekula R, Duncan I. Medication days' supply, adherence, wastage, and cost among chronic patients in Medicaid. Medicare Medicaid Res Rev. 2012;2 (3):E1-E13. doi:10.5600/mmrr.002.03.A04

9. Ministry of Health, Labour and Welfare, Minister's Secretariat, Statistics and Information Department, Social Statistics Division. Rules for health insurance-covered dispensing pharmacies and pharmacists. [Publication day; April 1, 2018]. Available from: http://elaws.e-gov.go.jp/ search/elawsSearch/elaws_search/1sg0500/detail?1awId= 332M50000100016\&openerCode=1. Accessed August 23, 2018. Japanese.

10. Golchin N, Frank SH, Vince A, Isham L, Meropol SB. Polypharmacy in the elderly. $J$ Res Pharm Pract. 2015;4(2):85-88. doi:10.4103/ 2279-042X.155755
Patient Preference and Adherence

\section{Publish your work in this journal}

Patient Preference and Adherence is an international, peer-reviewed, open access journal that focusing on the growing importance of patient preference and adherence throughout the therapeutic continuum. Patient satisfaction, acceptability, quality of life, compliance, persistence and their role in developing new therapeutic modalities and compounds to optimize clinical outcomes for existing disease

\section{Dovepress}

states are major areas of interest for the journal. This journal has been accepted for indexing on PubMed Central. The manuscript management system is completely online and includes a very quick and fair peer-review system, which is all easy to use. Visit http:// www.dovepress.com/testimonials.php to read real quotes from published authors. 